\title{
Missile System Equipment Operational Reliability Analysis
}

\author{
Baidong Yi* \\ 667\#, Jiefang road, Zhongshan District, Dalian City, Liaoning Province, China \\ *Corresponding author
}

\begin{abstract}
The concept and influence factors of missile system equipment operational reliability are analyzed, the missile system equipment operational reliability evaluation model is established, the missile system equipment operator's operation reliability value and the equipment reliability value are assessed by multilevel fuzzy comprehensive evaluation method, which is useful for evaluating the missile system equipment operational reliability, and providing reference method for other weapon system equipment operational reliability evaluation.
\end{abstract}

Keywords-missile system; equipment; operational reliability

\section{INTRODUCTION}

Missile system equipment operational reliability is very important for the missile system operation implementation, it is necessary to evaluate the missile system equipment operational reliability. As the influence factors of the missile system equipment operational reliability are relatively fuzzy, multilevel and incertitude, multilevel fuzzy comprehensive evaluation method is useful to assess the missile system equipment operational reliability.

The concept and influence factors of missile system equipment operational reliability are analyzed, the missile system equipment operational reliability evaluation model is established, and the missile system equipment operational reliability value is assessed through the multilevel fuzzy comprehensive evaluation method.

\section{INFLUENCE FACTORS OF MisSILE SYSTEM EQUIPMENT OPERATIONAL RELIABILITY}

Missile system equipment operational reliability is the equipment operator's operational reliability under combat environment with definite availability, which can assess the equipment operational reliability level. The influence factors of the equipment operational reliability are the equipment inherent reliability, combat environment and operator operation, which can be refenced by Liu Yangsong (1996) ${ }^{1}$.

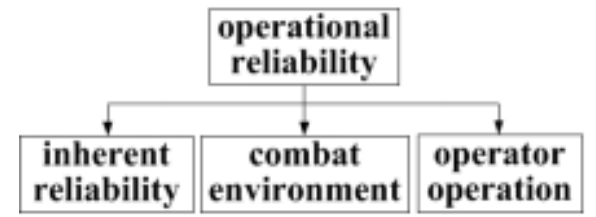

FIGURE I. INFLUENCE FACTORS OF MISSILE SYSTEM EQUIPMENT OPERATIONAL RELIABILITY

\section{Missile System EQUiPMENT OPERATIONAL RELIABILITY EVALUATION MODEL}

Assume that $R_{b s}$ is missile system equipment operational reliability, $R_{b s c}$ is the missile system equipment operator's operational reliability, $R_{b s h}$ is the missile system equipment reliability under combat environment.

When the missile system equipment is used by the operator, $R_{b s}$ can be calculated by $R_{b s}=R_{b s h} R_{b s c}$, which can be refenced by Wang Wuhong (1998) ${ }^{2}$.

When the missile system equipment isn't used by the operator, $R_{b s}$ can be calculated by $R_{b s}=R_{b s h}$.

\section{A. Missile System Equipment Operator's Operational Reliability Evaluation}

Through multilevel fuzzy comprehensive evaluation method, the missile system equipment operator's operational reliability $R_{b s c}$ is assessed. The method is based on the fuzzy relation principle, every factor is solely assessed, afterwards, all factors are synthetically assessed, the evaluation process is as follows.

\section{1) Evaluation factor aggregation establishment}

The influence factors of missile system equipment operator's operational reliability is shown in Figure 2, the evaluation factor aggregations are as follows.

$\mathrm{U}=\left\{\mathrm{U}_{1}, \mathrm{U}_{2}, \mathrm{U}_{3}, \mathrm{U}_{4}\right\} . \mathrm{U}_{1}=\left\{\mathrm{U}_{11}, \mathrm{U}_{12}, \mathrm{U}_{13}, \mathrm{U}_{14}, \mathrm{U}_{15}\right\}=\{$ military diathesis, knowledge framework, mental diathesis, habitude and culture $\} . \mathrm{U}_{2}=\left\{\mathrm{U}_{21}, \mathrm{U}_{22}, \mathrm{U}_{23}, \mathrm{U}_{24}, \mathrm{U}_{25}\right\}=\{$ cabin illuminance, cabin inside noise, cabin temperature and humidity, location layout, sea area combat environment $\} . \mathrm{U}_{3}=\left\{\mathrm{U}_{31}, \mathrm{U}_{32}, \mathrm{U}_{33}\right\}=$ \{wholesome code of organization, smooth organization, lashup organization capability $\} . \mathrm{U}_{4}=\left\{\mathrm{U}_{41}, \mathrm{U}_{42}, \mathrm{U}_{43}\right\}=$ \{equip- ment software reliability, equipment hardware reliability, equipment assistant decision-making capability . 


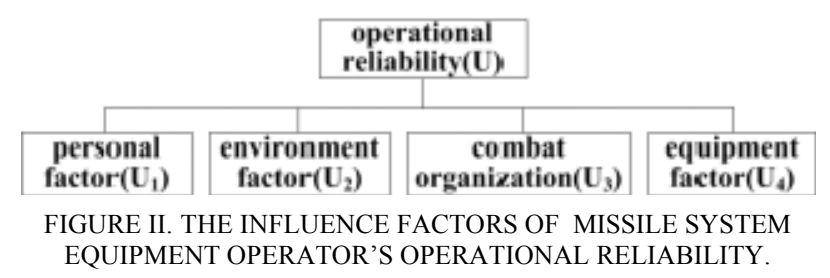

\section{2) Evaluation aggregation establishment}

Evaluation aggregation is the aggregation of evaluation results given by the evaluation object, which can be expressed as $\mathrm{V}=\left\{\mathrm{V}_{1}, \mathrm{~V}_{2}, \mathrm{~V}_{3}, \mathrm{~V}_{4}, \mathrm{~V}_{5}\right\}=\{$ high, relatively high, common, relatively low, low .

a) Influence factor weight calculation:The core question of the multilevel fuzzy comprehensive evaluation method is to calculate the influence factor weight. The influence factor weight can be obtained by the expert experiences, and can be obtained by the ameliorated hiberarchy analysis method. Based on the hiberarchy framework model, the influence factor weight determination process is as follows.

Through expert mark, single group factors are compared by one-to-one, the relative importance of the factor is determined. By three tag method, comparative matrix (defined by $\mathrm{G}$ ) can be obtained.

$$
G=\left[\begin{array}{cccc}
G_{11} & G_{12} & \cdots & G_{1 m} \\
G_{21} & G_{22} & \cdots & G_{2 m} \\
\vdots & \vdots & \vdots & \vdots \\
G_{m 1} & G_{m 2} & \cdots & G_{m m}
\end{array}\right]
$$

$$
G_{h f}= \begin{cases}2 & \text { the } \mathrm{h} \text {-th factor is more important than the } \mathrm{f} \text {-th factor } \\ 1 & \text { the h-th factor is of the same importance with the } \mathrm{f} \text {-th factor } \\ 0 & \text { the } \mathrm{f} \text {-th factor is more important than the } \mathrm{h} \text {-th factor }\end{cases}
$$

where $\mathrm{G}_{\mathrm{hf}}$ is comparative importance value between the h-th factor and the f-th factor. $G_{h h}=1,1 \leq \mathrm{h}, \mathrm{f} \leq \mathrm{m}$.

Assume that $r_{h}$ is the importance sort index, it can be calculated by

$$
r_{h}=\sum_{f=1}^{m} G_{h f}
$$

which can be refenced by Cai Kaiyuan (1996) ${ }^{3}$.

Assume that $r_{\max }$ is the maximum value of $r_{h}$, and $r_{\min }$ is the mimimum value of $r_{h}$, which can be calculated by $r_{\max }=\max \left\{r_{h}\right\}, r_{\min }=\min \left\{r_{h}\right\}$

Assume that $C$ is the judgement matrix, and $G_{h f}$ is the element of the matrix, which can be calculated by ${ }^{4}$

$$
C_{h f}= \begin{cases}\frac{r_{h}-r_{f}}{r_{\max }-r_{\min }}\left(k_{m}-1\right)+1 & r_{h} \geq r_{f} \\ {\left[\frac{r_{h}-r_{f}}{r_{\max }-r_{\min }}\left(k_{m}-1\right)+1\right]^{-1}} & r_{h}<r_{f}\end{cases}
$$

where $k_{m}=\frac{r_{\max }}{r_{\min }}$

Assume that $\mathrm{Q}$ is the transfer matrix of the judgement matrix, and $\mathrm{Q}_{\mathrm{hf}}$ is the element of the matrix, which can be calculated by

$$
Q_{h f}=\lg C_{h f}
$$

Assume that optimal transfer matrix is $Z$, and $Z_{h f}$ is the element of the matrix, which can be calculated by

$$
Z_{h f}=\frac{1}{m} \sum_{s=1}^{m}\left(Q_{h s}-Q_{f s}\right)
$$

Assume that $C^{\prime}$ is optimal consistent matrix of the judgement matrix, and $C_{h f}^{\prime}$ is the element of the matrix, which can be calculated by

$$
C_{h f}^{\prime}=10^{Z_{h f}}
$$

Influence factor weight determination is to obtain the eigenvector of the optimal consistent matrix, through root method, the process to calculate the influence factor weight is as follows.

Firstly, assume that $M_{h}$ is the product of every group elements of the matrix $C^{\prime}$, it can be calculated by ${ }^{5}$

$$
M_{h}=\prod_{f=1}^{m} C_{h f}^{\prime}
$$

Assume that $\overline{E_{h}}$ is the root of $M_{h}$, it can be calculated by

$$
\overline{E_{h}}=\sqrt[m]{M_{h}}
$$

Through unitary disposal of the vector $\bar{E}=\left(\overline{E_{1}}, \overline{E_{2}}, \cdots, \overline{E_{m}}\right)^{T}$, assume that the weight vector is $A=\left(A_{1}, A_{2}, \cdots, A_{m}\right)^{T}$, the h-th element $A_{h}(1 \leq \mathrm{h} \leq \mathrm{m})$ can be calculated by 


$$
A_{h}=\frac{\overline{E_{h}}}{\sum_{h=1}^{m} \overline{E_{h}}}
$$

b) Fuzzy evaluation of single factor: fuzzy evaluation of single factor is to obtain its subjection value based on the evaluation aggregation (defined by $\mathrm{V}$ ), assume that $r_{i j}$ is the subjection value of the evaluation factor (defined by $U_{i}$ ) with the evaluation grade (defined by $\mathrm{V}_{\mathrm{j}}$ ), and assume that $\mathrm{R}$ is fuzzy relation matrix, $\mathrm{R}$ can be defined by

$$
R=\left[\begin{array}{lllll}
r_{11} & r_{12} & r_{13} & r_{14} & r_{15} \\
r_{21} & r_{22} & r_{23} & r_{24} & r_{25} \\
r_{31} & r_{32} & r_{33} & r_{34} & r_{35} \\
r_{41} & r_{42} & r_{43} & r_{44} & r_{45}
\end{array}\right]
$$

For the subjection value of the qualitative factor, it can be calculated by the expert method, assume that for $n$ experts, if $d$ experts consider that the qualitative factor is of the evaluation grade (defined by $V_{x}$ ), the subjection value of the qualitative factor is $\mathrm{d} / \mathrm{n}$.

In Figure 2, the quantitative factors are beneficial factors. For certain quantitative factor, assume that its quantitative value is $\mathrm{z}$, and $r_{d}$ is the subjection value of the evaluation grade, and the critical value of every evaluation grade of $\mathrm{V}$ is $\mathrm{J}_{1} \sim \mathrm{J}_{6} . r_{d}$ can be calculated by

$$
r_{d}= \begin{cases}0 & Z<J_{j} \\ \left(Z-J_{j}\right) /\left(J_{j+1}-J_{j}\right) & J_{j} \leq Z<J_{j+1} \\ 1 & Z \geq J_{j+1}\end{cases}
$$

\section{B. Fuzzy Comprehensive Evaluation}

For the evaluation aggregation $U$, assume that $A_{1}$ is the root vector of the $U$, and $B$ is the evaluation matrix of $U, B$ can be calculated by $B=A_{1} \circ R=\left(B_{1}, B_{2}, B_{3}, B_{4}, B_{5}\right)$.

where $\circ$ is fuzzy operation sign. The fuzzy operation sign used in the fuzzy comprehensive evaluation method is $M(\cdot, \oplus) . a \oplus b$ can be calculated by

$$
a \oplus b=\min (a+b, 1)
$$

After unitary dispoal of fuzzy comprehensive evaluation, through maximum subjection value method, the missile system equipment operator's operational reliability $R_{b s c}$ can be calculated by

$$
R_{b s c}=\mu \alpha \xi\left\{\mathrm{B}_{1}, \mathrm{~B}_{2}, \mathrm{~B}_{3}, \mathrm{~B}_{4}, \mathrm{~B}_{5}\right\}
$$

\section{Missile System EQuiPMENT OPERATIONAL RELIABILITY EVALUATION MODEL UNDER COMBAT ENVIRONMENT}

The influence factors of missile system equipment operational reliability under combat environment are shown in Figure 3, missile system equipment operational reliability under combat environment factor is defined by $\mathrm{W}$, combat environment factor is defined by $\mathrm{W}_{1}$, the inherent reliability of the equipment is defined by $\mathrm{W}_{2}$, the meteorologic environment factor is defined by $\mathrm{W}_{11}$, the electromagnetism environment factor is defined by $\mathrm{W}_{12}$, the ship environment factor is defined by $\mathrm{W}_{13}$, the equipment software reliability factor is defined by $\mathrm{W}_{21}$, the equipment hardware reliability factor is defined by $\mathrm{W}_{22}$.

For the evaluation aggregation $\mathrm{V}$, based on the ameliorated hiberarchy analysis method, assume that $\mathrm{A}_{2}$ is the weight vector for $\mathrm{V}$, and $\mathrm{C}$ is the evaluation matrix for $\mathrm{V}, \mathrm{C}$ can be calculated by $\mathrm{C}=\mathrm{A}_{2} \circ \mathrm{R}=\left(\mathrm{C}_{1}, \mathrm{C}_{2}, \mathrm{C}_{3}, \mathrm{C}_{4}, \mathrm{C}_{5}\right)$.

Through maximum subjection value method, missile system equipment operational reliability under combat environment $R_{b s h}$ can be calculated by

$$
R_{b s h}=\mu \alpha \xi\left\{\mathrm{X}_{1}, \mathrm{X}_{2}, \mathrm{X}_{3}, \mathrm{X}_{4}, \mathrm{X}_{5}\right\}
$$

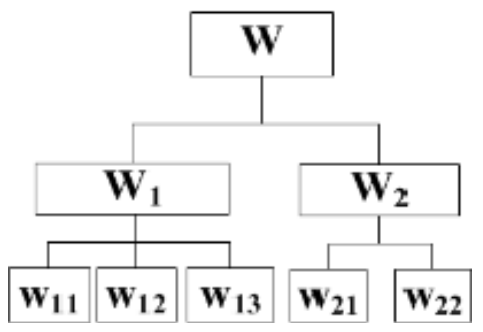

FIGURE III. THE INFLUENCE FACTORS OF MISSILE SYSTEM EQUIPMENT OPERATIONAL RELIABILITY UNDER COMBAT ENVIRONMENT.

\section{SUMMARY}

Based on the concept and influence factors of missile system equipment operational reliability, the missile system equipment operational reliability evaluation method is proposed, which can assess the missile system equipment operational reliability under combat environment, and provide research method for the missile system equipment operational reliability evaluation, and provide reference method for other weapon system equipment operational reliability evaluation.

\section{REFERENCES}

[1] Liu Yangsong. Fuzzy Reliability and Application. Mass Reliability, 12 (10). (1996)

[2] Wang Wuhong. Human-machine System Reliability Analysis Development. System Engineering Transaction, 13(1). (1998) 
[3] Cai Kaiyuan. Introduction to Fuzzy Reliability. Kluwer Academic Publishers, China, 1996.

[4] J. van der Geer, J.A.J. Hanraads, R.A. Lupton, The art of writing a scientific article, J. Sci. Commun. 163 (2000) 51-59.

[5] W. Strunk Jr., E.B. White, The Elements of Style, third ed., Macmillan, New York, 1979 